\title{
Adapting to the New Normal: An experience of a higher education institution in conducting workshops on Professionalism \& Ethics in Medical Practice
}

\author{
Ihsan, F.R. \& Molligoda, H.D.
}

\begin{abstract}
Introduction: The erosion of many attributes of professionalism has raised concerns among medical educators which led to a mandatory module on Professionalism and Ethics being integrated into Postgraduate MD programmes in Sri Lanka. The transition of the face-to-face workshop to an online programme is one of the many ways the PGIM rose to the challenge of maintaining high-quality education while ensuring safety of trainees and faculty members during the COVID-19 pandemic. Although electronic learning is widely used, there is minimal research on its use in postgraduate medical education in developing countries such as Sri Lanka. This study aims to evaluate the response of postgraduate medical students to the transition of workshops on professionalism and ethics to an online platform.
\end{abstract}

Method: A total of 148 of the 157 postgraduate students who completed the module in May 2020, participated in the study by filling the online semi-structured, self-administered questionnaire. Descriptive statistics were employed to analyze the responses to close-ended questions and the responses to open- ended questions were analyzed for recurring themes.

Results: The online platform used was rated as very effective/effective by $135(91.22 \%)$ students, while $70(47.3 \%)$ asked questions during the teaching sessions. Majority of students;141(95.27\%) perceived the overall educational experience as excellent or good. Most students logged in using mobile phones, $59(39.9 \%)$ and tablet $40(27.0 \%)$, demonstrating the need to develop mobile friendly online programmes. Accessibility; a major limitation to online educational programmes in developing countries, may not be as significant as perceived to be among postgraduate medical students. Majority of students prefer a virtual mode of delivery in the future.

Conclusion: The study demonstrates that students perceived the transition of the face-to-face workshop on professionalism and ethics to an online platform as a valuable educational experience. COVID-19 has adversely affected medical education all over the world. Today the classes are conducted through online platforms. Therefore, a study was conducted to evaluate the response of Sri Lankan medical postgraduate students to the transition of workshops on professionalism and ethics to an online platform.

Keywords: Professionalism \& Ethics, Workshop, E-learning, Postgraduate medical education, Pandemic, distance learning, online learning, COVID-19

\section{Introduction}

Medical Professionalism, based on patient welfare, autonomy and social justice, has been declared a core competency requirement of

Postgraduate Institute of Medicine, University of Colombo, Sri Lanka

Email: rizka.ihsan@gmail.com the Accreditation Council for Graduate Medical Education (ACGME)(Huddle, 2005). Although the term rarely encompasses a universal definition, it has been recognized as a social contract between doctors and society to maintain public trust in the profession, throughout the history of medicine (Chandratilake et al., 2012).

DOI: http://doi.org/10.4038/seajme.v14i2.255

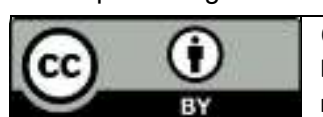

(c) SEAJME. This is an Open Access article distributed under the terms of the Creative Commons Attribution License (http://creativecommons.org/licenses/by/4.0/), which permits unrestricted use, distribution, and reproduction in any medium, provided the original author and source are credited 
In the recent years, erosion of many attributes of professionalism has raised concerns among medical educators. The current global phenomenon of overemphasis of the vocational element and minimal expression of selfregulation has resulted in the lack of professionalism in the field of medicine and Sri Lanka is no exception. Medicine is meant to be a profession that practices and displays high standards of self-regulation(Chandratilake, 2016). Though medical management skills are considered eminent among Sri Lankan healthcare workers, lack of professionalism in the field is an increasing subject of scrutiny.

A question that loomed over the last few decades was 'can professionalism be taught?' as teaching and learning are two entirely different processes. Amidst the existence of the question of best approach to teaching professionalism, studies have revealed that professionalism can, in fact be taught through role modeling, mentoring, reflections, selfawareness and constructive analysis of one's capacities(David T. Stern, 2003). Therefore, regulatory and professional bodies worldwide have adopted many educational tools to teach professionalism implicitly and explicitly.

The Postgraduate Institute of Medicine (PGIM), Sri Lanka is under the purview of the University of Colombo and is the only institute providing specialist training for medical doctors in the country. In view of this pressing call for professionalism, the PGIM formulated and integrated a compulsory workshop on Professionalism and Ethics into Postgraduate MD programmes from year 2014 onwards.

An interactive face-to-face workshop was designed and implemented by experts in medical education and clinical specialists in various disciplines to address the gaps in trainee's knowledge in professionalism, based on observations in the clinical setting. The workshop was designed to be conducted over a period of 04 days, in 02 days sessions, fortnightly. An interval of 02 weeks was included in the workshop to minimize interference in ongoing clinical training. Each workshop consisted of multiple three-hour sessions using an array of educational methods such as role plays, small group activities and case-based discussions to promote critical and reflective thinking.

The Coronavirus disease 2019 (abbreviated "COVID- 19") that emerged in December 2019 in Wuhan, proved to be a highly transmittable and pathogenic viral infection claiming more than 1, 914, 000 confirmed cases and over
123,010 reported deaths globally by April 15,2020 , presenting a unique challenge to education worldwide(Shereen et al., 2020, World Health Organization, 2020, April 15). The Ministry of Higher Education requested all universities to close from March 13, 2020 onwards, as the second confirmed Covid-19 patient in Sri Lanka was reported on March 11,2020(Epidemiology Unit, 2020, April 15). As the total number of confirmed cases rose to 66 , the state imposed a nationwide lockdown on March 20, in escalating efforts to slow down the progress of the disease(Economynext, July $6,2020)$.

Although the state began to ease lockdown restrictions on May 11, educational institutes realized that with no cure or vaccine in the foreseeable future, adherence to disease control and prevention measures and adaptation to this new normal are crucial. Transformation of the face-to-face workshop on Professionalism and Ethics to an online 04 days programme is one of the many ways the PGIM rose to the challenge of maintaining high-quality education while ensuring safety of trainees and faculty members.

Electronic learning (e-learning) is a pedagogical approach that has been recognized for its flexibility, engagement and accessibility among its many unique characteristics. Studies have brought to light that while e-learning possesses its own strengths and weaknesses, it does not demonstrate significant difference in outcome or exam performance in comparison to traditional teaching methods(Dawd, 2016). Hence, synchronous e-learning via Zoom to provide participants an experience nearly close to traditional learning with minimal feels of social isolation was adopted.

Professionalism cannot be viewed as a brief, static topic during training but a lifelong pursuit and this compulsory workshop has been created to provide an opportunity to foster and instill these traits in future specialists. However, there has been a resistance to the utilization of online platforms in postgraduate medical studies in Sri Lanka that has resulted in a lag in the development of distance learning programmes. Therefore, there is currently minimal evidence into the use of an online platform among postgraduate medical students in Sri Lanka.

This study aims to evaluate the response of Sri Lankan medical postgraduate trainees to the transition of workshops on professionalism and 
ethics to an online platform, the first study to be published in the Sri Lankan context.

\section{Methods}

The first online workshop on "Professionalism and Ethics in Medical Practice" was conducted on zoom online platform over a period of four days on two consecutive days for two consecutive weeks. This was facilitated by the PGIM via the specialized Internet Service Provider; Lanka Education and Research Network (LEARN), that interconnects multiple educational universities. An online registration procedure similar to that of the face-to-face workshop was followed. The link for the session was mailed two weeks prior to the scheduled dates to all 187 registered participants from 33 specialties, who were at different stages of their postgraduate training.

Identification of resource persons for the virtual session was on a volunteer basis from the pool of resource persons for face-to-face workshops, a routine procedure followed for face-to-face workshops. Resource persons were given the freedom to make necessary changes to their existing structure and design of the programme to adapt to and improve the effectiveness of the virtual platform. Each resource person was given a period of 3hours for their topic of discussion with a short break of 15 mins in between excluding the lunch hour; similar to time allocations of regular face-toface sessions. All trainees were sent a reminder via electronic mail two days prior to the session. Attendance was monitored and recorded by the host; PGIM.

At the end of the session, an online semistructured questionnaire developed by using google forms with an information sheet and consent form appended to it was sent to all participants who completed the programme. Administrative approval was acquired from the Director, PGIM for data collection. The questionnaire consisted of two parts: Part 01 consisted of demographic details and explored the technical aspect while the experience of network issues was sought via an open-ended question. Part 02 included items on student perceptions on multiple aspects of learning experience; course organization, communication, use of visual aids, interaction, quality of content, online material and pace of course using a rating scale from 1-5 (1= ineffective and $5=$ very effective). Furthermore, students rated their opinion on meeting course outcomes using a rating scale from 1-5 $(1=$ not at all and $5=$ very well) and overall educational experience using a rating scale of 1-4 (1= excellent and $4=$ poor). The students were also asked the mode of delivery they would opt for, if a second phase of the course were to be implemented.

The data gathered from the questionnaire were analyzed using descriptive statistics and data gathered from the open-ended question were coded and analyzed for recurring themes.

\section{Results}

Although a total of 245 trainees registered for the programme, 187 trainees participated, and only 157 completed all four modules. A total of 148 trainees from 33 specialties responded to the questionnaire.

. A total of $135(91.22 \%)$ students stated that the platform utilized to conduct the educational activity was very effective or effective (Table 01).

Aspects related to the conduct of the course were rated positively by the trainees (table 2). The average mean score for communication, faculty/student interaction \& discussion and the use of visual aids were perceived to be high with mean scores more than the average cutoff rating of 3 on a five-point Likert scale.

The mean scores for course organization, online material provided, quality of content and pace of the course indicate that these aspects were perceived as effective. Seventy $(47.3 \%)$ trainees stated that they asked questions from the resource persons during the teaching session.

Table 3 indicates the trainees' opinion on achieving course outcomes. They felt that their learning increased in this course and acquired a broad knowledge on professionalism which helped progress towards achieving course objectives. Trainees indicated that the course helped them think independently about professionalism and ethics and reflectively develop a personal code of values and ethics. Furthermore, students indicated an increase in interest in the overall subject while the session met their expectations well.

The students rated the quality of educational advice received in the programme and overall educational experience along a 4-point Likert scale (Table 4). Most trainees $90(60.81 \%)$ said the quality of educational advice received during the programme was good, while $50(33.79 \%)$ indicated they received excellent advice and 08(5.40\%) felt they received fair educational advice during the programme. Ninety-seven $(65.54 \%)$ students felt the overall educational experience was good whereas 44 
(29.73\%) students rated the overall educational experience excellent and $7(4.73 \%)$ students rated the same aspect fair.

Most students 126(85.14\%) preferred an online mode of delivery for future conduct of the programme (Table 5).

One hundred and seven trainees $(72.29 \%)$ participated from home, while 36(24.32\%) logged in from their workplaces. Majority of trainees,59(39.99\%) logged in via mobile phones, $81(54.7 \%)$ via tablets and laptops (Table 6). Most of the trainees 59(39.9\%) had used mobile phones to log into the programme whereas $41(27.70 \%)$ students had used laptops and 40(27\%) students had utilized tablets to do so (Table 7).

Fifty-four $(64.00 \%)$ trainees had encountered technical issues during the online teaching learning activity, and network failure was identified as the most encountered technical issue (Table $07 \&$ 08). Responses to the openended questions indicated that 17 students solved the issue by attempting to connect multiple times whereas 11 students experienced a spontaneous resolve of the issue.

\section{Discussion}

Continuing medical education during a pandemic while ensuring safety of students, staff and all other stakeholders requires a great deal of flexibility from both learners and educators. E-learning has been recognized as one of the most dynamic responses to the growing need for education. It is argued that teaching attributes of professionalism and ethics that involve changes in behavior and attitudes is challenging when using online platforms. However, several studies have proven that innovative approaches to teaching professionalism and ethics via a virtual platform supports professional development(McEvoy et al., 2012, NADEAU et al., 2016).

Learners' expectations are recognized challenges that may interfere with the effectiveness of online courses(Kebritchi et al., 2017). However, this study indicates that the programme met students' expectations well while aspects related to the conduct of the course and achieving course outcomes were rated positively, majority of trainees rated the overall educational experience and quality of educational advice received during the programme; good. Communication and time management which are identified critical issues affecting the quality of online education were perceived as effective in this study, by
trainees(Bassoppo-Moyo, 2006). This is further supported as most students rated the faculty and student interaction as effective. More than half of the participants $78(52.7 \%)$ who did not ask any questions, are also considered active learners as online listening and observing consist of engagement with the content, thought, and reflection(Hrastinski and Education, 2009).

Content cannot simply be copied from face-toface to an online setting. The use of multimedia to enhance course content and synchronous mode of communication to promote student engagement are several forms in which the course adopted Miller's strategies for effective instruction of online courses(Miller et al., 1999). Students' satisfaction of these aspects of the course are depicted in ratings of course organization, use of visual aids, quality of content and online material as effective.

Contrary to popular local belief, several studies reveal no significant difference in learning outcomes, between traditional and e-learning modes of delivery (Dawd, 2016, Pei and Wu, 2019, Stack and Learning, 2015) which validate the findings of this study.

The 135(91\%) students rated the platform utilized to conduct the educational activity; online/zoom, effective or very effective and preference to participate in a virtual educational session in the future, displays learners' readiness to attend online courses which is one of the major issues identified in previous studies(Kebritchi et al., 2017). Although learning styles and technical skills of the students are obstacles to successful participation in an online course, the flexibility provided and minimal time consumption on travelling to attend an otherwise physical educational session, may have contributed to the preference of a virtual platform among these busy residents working in various parts of the country. Furthermore, as this course on professionalism and ethics is a compulsory component of their curricular, it may have provided the self-direction and self-motivation required to participate in the course(Hung et al., 2010).

Participants were able to attend these workshops from different areas of the country from a convenient location, cost effectively without having to travel to the training center; a step towards offering learner centered educational opportunities. A perceived lack of access to computers and internet facilities has been a limitation to developing online workshops for postgraduate medical trainees in 
Sri Lanka(Raviraj et al., 2020). Over one third of trainees 54(36.48\%) had encountered technical issues during the online training sessions and the most frequently encountered issue of network failures may owe to the fact that certain remote areas of the country do not have proper broadband coverage(Raviraj et al., $2020)$. Of the 148 trainees who completed all the modules, 94(63.52\%) had no technical issues. However, majority of trainees who faced this issue had overcome the issue by attempting to reconnect multiple times, changing the login location and changing the internet provider, whereas some experienced a spontaneous resolve, indicating that the gravity of the limitation identified may not be as significant as perceived to be.

Majority of trainees $59(39.9 \%)$ used mobile phones to log into the programme whereas most others $81(54.70 \%)$ used laptops and tablets. This demonstrates the need to develop mobile friendly online programmes in order to provide equitable educational opportunities. Trainees encountered login errors $07(11.32 \%)$ which were resolved by the institution when approached. The institution has to take necessary steps towards preventing the occurrence of such avoidable technical errors in the future and utilize a user-friendly interface.

\section{Limitations}

This descriptive study to explore student perceptions on the transition of workshops on professionalism and ethics to an online platform has several limitations. The lack of an assessment; all trainees who were logged in throughout the session were considered to have completed the educational session. Although the face-to-face workshop follows a similar format, a mere record of attendance was the only requirement to complete the course. Learning styles differ, not all learners can successfully participate in online courses as it mostly suits self-motivated and self-directed learners(Boyd and Development, 2004). An assessment would have further clarified the effectiveness of the programme and provided insight to the degree of adaptability to improve the course.

This study does not explore the trainer's point of view, but only that of the trainee. Changing role of the faculty, factors pertaining to transition from face-to-face to online such as communication barriers, interests, preparation and teaching styles are aspects that have major impact on the conduct/effectiveness of an online course (Kebritchi et al., 2017). Reviewing their perspective may bring to light recognized significant challenges pertaining to online teaching; requiring training on content development, translation of material into online medium, online teaching tools and online delivery.

Despite these limitations our study demonstrates that postgraduate students embraced online teaching on professionalism and ethics and compliance with similar researches indicate that successful online delivery of postgraduate courses and postgraduate courses that deem human interaction fundamental can be implemented in our setting.

\section{Conclusion}

This study demonstrated that students perceived the transition of the face-to-face workshop on professionalism and ethics to an online platform as a valuable educational experience. Aspects pertaining to conduct of the course, factors associated to student engagement, achieving course objectives and educational experience were rated positively while the factors associated to accessibility display future feasibility. More research is needed to explore the trainer's response of the same to acquire a holistic view in order to improve effectiveness of the programme.

One can always argues that 'traditional' teaching methods are more effective. But these are times that require us to use each mode of teaching to its strengths and provide equitable educational opportunities for all.

\section{Conflict of Interest}

The authors declare no conflict of interest.

\section{Ethics Committee Approval}

As this was an educational evaluation, ethics approval was not requested.

\section{Acknowledgements}

The director, resource persons of the Professionalism and Ethics module and staff of Medical Education Resource Centre of the Postgraduate Institute of Medicine.

\section{References}

Bassoppo-moyo, T. C. J. I. J. O. I. M. 2006. Evaluating eLearning: A front-end, process and post hoc approach. 33, 7-23.

Boyd, D. J. N. H. I. A. E. \& Development, H. R. 2004. The characteristics of successful online students. 18, 31-39. 
Chandratilake, M., Mcaleer, S. \& Gibson, J. J. C. M. J. 2012. Professionalism: the indicator of a civilised and exemplary medical profession. 57.

Chandratilake, M. N. J. P. O. 2016. Professionalism in medicine; the transition of a movable feast and its implications for clinical and educational practices. 1-8.

David T. Stern, M., PHD 2003. Can Professionalism be Taught? AMA Journa of Ethics, 5, Number 12.

Dawd, S. J. E. J. O. H. S. 2016. The promise of e-platform technology in medical education. 26, 173-178.

Economynext. July 6,2020. Sri Lanka's state universities to re-open subject to 11 conditions [Online]. Echelon. Available: https://economynext.com/sri-lankas-stateuniversities-to-re-open-subject-to-11conditions-71706/ [Accessed 2020].

Epidemiology Unit, M. O. H., Sri Lanka 2020, April 15. Coronavirus disease 2019 Situation Report.

Hrastinski, S. J. C. \& Education 2009. A theory of online learning as online participation. 52, 78-82.

Huddle, T. S. 2005. Viewpoint:: Teaching Professionalism: Is Medical Morality a Competency? 80, 885-891.

Hung, M.-L., Chou, C., Chen, C.-H., Own, Z.-Y. J. C. \& Education 2010. Learner readiness for online learning: Scale development and student perceptions. 55, 1080-1090.

Kebritchi, M., Lipschuetz, A. \& Santiague, L. J. J. O. E. T. S. 2017. Issues and challenges for teaching successful online courses in higher education: A literature review. 46, 429.
Mcevoy, M., Butler, B. \& Maccarrick, G. J. T. C. T. 2012. Teaching professionalism through virtual means. 9, 32-36.

Miller, S. M., Miller, K. L. J. J. O. E. T. \& Society 1999. Using instructional theory to facilitate communication in web-based courses. 2, 106-114.

Nadeau, M. T., Tysinger, J., Wiemers, M. J. J. O. A. I. M. E. \& Professionalism 2016. A case-based approach for teaching professionalism to residents with online discussions. 4, 1.

Pei, L. \& Wu, H. 2019. Does online learning work better than offline learning in undergraduate medical education? A systematic review and meta-analysis. Medical education online, 24, 16665381666538.

Raviraj, S., PS, W., Anthony, A.A., Wijesinghe, R.A.N.K., Bowatte, S., Wickramaratne, N., Pathirana, K.D., Pilapitiya, S., Edirisinghe, S., Hettiarachchi, D. and Kohombange, C., 2020. The new normal of medical educationchallenges and opportunities. South-East Asian Journal of Medical Education, 14(1).

Shereen, M. A., Khan, S., Kazmi, A., Bashir, N. \& Siddique, R. J. J. O. A. R. 2020. COVID19 infection: origin, transmission, and characteristics of human coronaviruses.

Stack, S. J. I. J. F. T. S. O. T. \& Learning 2015. Learning Outcomes in an online vs traditional course. 9, n1.

World Health Organization. 2020, April 15. Coronavirus disease (COVID-2019) situation reports [Online]. Available: https://www.who.int/docs/defaultsource/coronaviruse/situationreports/20200415-sitrep-86-covid19.pdf?sfvrsn=c615ea20_2 [Accessed]. 